\title{
Electrochemical determination of total reducing sugars from bioethanol production using glassy carbon electrode modified with graphene oxide containing copper nanoparticles
}

\author{
Flávia Camilo Unterman Santos ${ }^{\mathrm{a}, 1}$, Leonardo Lataro Paim ${ }^{\mathrm{b}, 2}$, José Luiz da Silva ${ }^{\mathrm{a}, *}$, \\ Nelson Ramos Stradiotto ${ }^{\mathrm{a}, 1}$ \\ a Institute of Chemistry, UNESP - Univ Estadual Paulista, Campus Araraquara, Department of Analytical Chemistry, Prof. Francisco Degni Street 55, Jardim Quitandinha, \\ 14800-060 Araraquara, SP, Brazil \\ ${ }^{\mathrm{b}}$ Campus de Rosana, UNESP - Univ Estadual Paulista, CCEE - Energy Engineering, Barrageiros Avenue 1881, Centro, 19274-000 Rosana, SP, Brazil
}

\section{H I G H L I G H T S}

- A electrochemical sensor modified was proposed with GO containing

CuNPs using PAD technique.

- The detection limit reached $6.4 \times 10^{-6} \mathrm{~mol} \mathrm{~L}^{-1}$ in a wide linear range from $2.0 \times 10^{-5}$ to $4.4 \times 10^{-4}$

- The developed method is fast and simple compared to classical methods currently used.

- The sensor showed quick response, sensitivity, accuracy and selectivity.

- The sensor was successfully applied to detect total reducing sugars in residual waters samples.

\section{A R T I C L E I N F O}

\section{Article history:}

Received 7 July 2015

Received in revised form 12 September 2015

Accepted 17 September 2015

Available online 28 September 2015

\section{Keywords:}

Reducing sugar

Bioethanol production

Pulsed amperometry

Graphene oxide

Copper nanoparticles
G R A P H I C A L A B S T R A C T

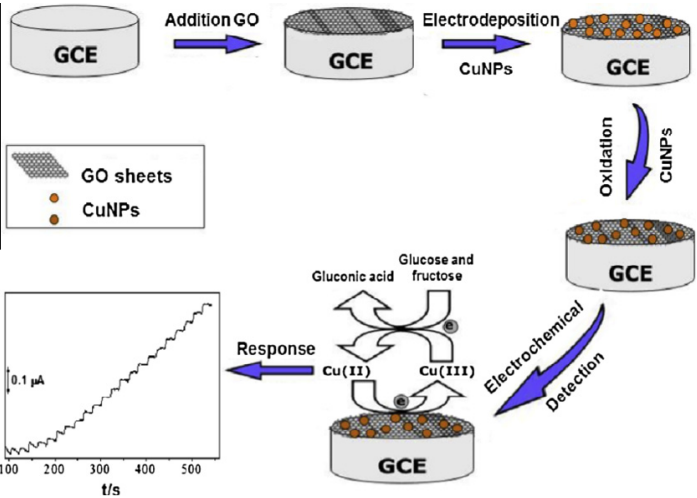

\section{A B S T R A C T}

This work presents the analytical method development for total reducing sugars determination in residual water samples obtained from sugarcane processing for ethanol production. This method was developed using pulsed amperometry with a glassy carbon electrode modified with graphene oxide containing copper nanoparticles. With pulsed amperometry detection was achieved a limit of detection of $6.4 \times 10^{-6} \mathrm{~mol} \mathrm{~L}^{-1}$. The amperometric sensitivity was $1.6 \times 10^{-2} \mathrm{~A} \mathrm{~mol}^{-1} \mathrm{~L}$. The recovery study showed that the method has good accuracy and repeatability, with recovery of $92.8 \pm 0.5 \%$. Experiment results obtained showed that the sensor has good long-term stability, sensitivity and is interference free, and the method developed is simple and fast.

(c) 2015 Elsevier Ltd. All rights reserved.

\footnotetext{
* Corresponding author. Tel.: +55 01633019519.

E-mail address: silva_jluiz@yahoo.com.br (J. Luiz da Silva).

1 Tel.: +55 01633019519 .

2 Tel: +5501832849200 .
}

\section{Introduction}

Nowadays, the bioenergy sector is facing a major challenge: to ensure and prove its sustainability. Environmental issues such as the availability of fossil fuels and environmental problems generated from their use [1], as well as economic and geopolitical 
reasons put emphasis in the search for clean and renewable energy sources. In this search, biofuels derived from different biomass stands out as a potential source, as well as the ethanol derived from sugarcane [2].

The chemical composition of sugarcane is very variable depending on the physical and chemical properties of the soil, climate and maturation stage [3]. The two main fractions of sugarcane as regards to its processing are the fiber and the broth, the latter being the raw material for the production of ethanol. The sugarcane broth is an impure solution of sucrose, glucose and fructose. Sucrose is in larger amount, having an average composition of $14 \%$, while for others sugars, depending upon the state of maturation is $0.4 \%$ [4].

Monosaccharides like glucose and fructose are the two types of reducing sugars found in sugarcane broth, they receive this name due to the presence of free ketonic carbonyl group, able to oxidize in the presence of oxidizing agents in alkaline solutions. However, sucrose is a disaccharide that does not have this characteristic, so it is referred to as a non-reducing sugar. The total reducing sugars represent the sum of reducing sugars and inverted sucrose. The inverted sucrose is the sucrose present in sugarcane broth that converts to reducing sugars (glucose and fructose) by acid hydrolysis, and thus can be quantified.

The determination of reducing sugars in various stages of the processing of sugarcane has great importance because it allows evaluating the quality of the raw material used to produce ethanol as well as possible losses enabling the optimization of production ensuring a better use of the raw material. Studies in the literature for determination of reducing sugars in different matrices showed that the classical chemical methods known for the analysis of reducing sugars are mostly based on reduction of copper ions in alkaline solutions - Fehling Solutions - [5]. There are also those based on the dehydration of sugars by using concentrated acid, with subsequent staining with organic compounds [6], or the simple reduction of organic compounds, forming other measurable coloring compounds in the visible region $[7,8]$.

Among these methods, the Somogyi-Nelson is widely applied in the sugarcane production to quantify the reducing sugars content in different samples providing reliable and accurate results for the industrial losses in general. However, this method, has major disadvantages such as relatively large analysis time, use of controlled temperature as well as low selectivity because it is prone to interference from other molecules that can act as reducing agents [9].

Most recently, some studies have shown the determination of glucose and fructose using non-enzymatic amperometric sensors $[10,11]$. A study was performed for applying a non-enzymatic glucose sensor in biological samples using a lead-tin oxide electrode modified with copper oxide microfibres (CuO-NPs) showing satisfactory results for biological samples [10]. Cobalt oxide-doped copper oxide composite nanofibers (CCNFs) were successfully achieved via electrospinning followed by thermal treatment processes and then exploited as active electrode material for direct enzyme-free fructose detection by cyclic voltammetry and amperometry [11].

Copper as an electrode material is of interest for analysis of carbohydrates and amino acids [12-15] because of the possibility of performing amperometric detection at a constant potential in solutions with a high value of $\mathrm{pH}$. In comparison to $\mathrm{Pt}, \mathrm{Au}, \mathrm{Ni}, \mathrm{Ag}$ and $\mathrm{Co}, \mathrm{Cu}$ was reported to be better in terms of range of response, detection limit, and especially stability [12].

Recent trends in the use of chemically modified electrodes (CMEs) in electrochemical detection systems are searching for new materials that can be operated without loss of the electrode activity, at constant applied potential [16]. Among these materials used for modification, the metallic nanoparticles (NPs) have been widely studied due to their physical and chemical properties, which differ of their bulk material [15]. NPs can display unique advantages over macroelectrodes, such as, enhancement of mass transport, higher signal-to-noise ratio, electrocatalysis, high surface area and effective control over the microenvironment of the electrode [17,18].

In this context, graphene also stands out because of its twodimensional plane, which provides itself with a large specific surface area for the immobilization of large amount of substances including a wide range of metals, nanoparticles, biomolecules, etc. Since every atom in a graphene is a surface atom, molecular interaction and thus electron transport through graphene can be highly sensitive to absorbed molecules [19]. Due to these properties, graphene has the ability to promote electron transfer reactions when used as an electrode, which provides an inexpensive alternative to carbon nanotubes [20].

CMEs with copper nanoparticles and graphene were used for electrochemical determination of glucose by flow injection analysis (FIA) and amperometry. Many advantages were found for the proposed system including high sensitivity and stability. Wide range of linearity and good reproducibility $[21,22]$. Chen and coauthors [23] prepared microdisc electrodes of graphene-copper nanoparticle composite by the in situ chemical reduction. The results indicated that copper nanoparticles with an average diameter of $20.8 \mathrm{~nm}$ were successfully deposited on graphene nanosheets. The CMEs were applied for sensing carbohydrates in combination with cyclic voltammetry and capillary electrophoresis. The sensitivity and detection limits were determined to be $85.96 \mathrm{nA} / \mathrm{mM}$ and $0.87 \mu \mathrm{M}$ for mannitol, $52.63 \mathrm{nA} / \mathrm{mM}$ and $1.42 \mu \mathrm{M}$ for sucrose, $50.88 \mathrm{nA} / \mathrm{mM}$ and $1.47 \mu \mathrm{M}$ for lactose, $63.16 \mathrm{nA} / \mathrm{mM}$ and $1.19 \mu \mathrm{M}$ for glucose, and $45.61 \mathrm{nA} / \mathrm{mM}$ and $1.64 \mu \mathrm{M}$ for fructose, respectively [23].

The determination of reducing sugar content is extremely important in studies that provide a greater appreciation of waste materials, in particular, development of processes for production of ethanol from sugarcane. Thus, the scope of the present work was the development of a glassy carbon electrode (GCE) modified with graphene oxide (GO) containing copper nanoparticles for the simultaneous determination of glucose and fructose, which are the reducing sugars, in residual waters from ethanol production plant. The technique employed in this study was the pulsed amperometry, which solves the problem of losing activity alternating anode and cathode polarization to clean and reactivate the electrode surface [24-26]. After an extensive literature review, we could not find any work involving the simultaneous determination of glucose and fructose by electroanalytical techniques in wastes from ethanol production plant. Therefore, this study can overcome one scientific lack with the development of a new electroanalytical tool, which should contribute to the better use of sugarcane as well as to improve the production process by reducing possible losses.

\section{Experimental}

\subsection{Reagents and solutions}

Solutions were prepared from analytical-reagent grade chemicals without further purification and by using ultrapure water (MILLI-Q). Sodium hydroxide ( $\geqslant 98 \%$ ), copper sulfate pentahydrate $(\geqslant 98 \%)$, glucose $(\geqslant 97 \%)$, fructose $(\geqslant 97 \%)$, sucrose $(\geqslant 97 \%)$, graphene oxide $\left(2 \mathrm{mg} \mathrm{mL}^{-1}\right)$, Nafion ${ }^{\circledR} 117$ solution, sulphuric acid (98\% w/w) were obtained from Sigma-Aldrich, hydrochloridric acid $(37 \% \mathrm{w} / \mathrm{w})$ from J.T. Baker and ethanol absolute P.A from Merck. The carbohydrates solutions were prepared with ultrapure water (MILLI-Q). Residual waters sample was supplied by a sugarcane plant in Araraquara, São Palo, Brazil. 


\subsection{Apparatus}

An Autolab PGSTAT-30 potentiostat/galvanostat controlled with the General - Purpose Electrochemical System (GPES) software (Eco Chemie B.V.) was used for electrochemical measurements. Cyclic voltammetry (CV) and pulsed amperometry was done in a conventional cell three-electrode using the glassy carbon (geometric area: $0.070 \mathrm{~cm}^{2}$ ) modified with graphene oxide and copper nanoparticles working electrode (NPsCu-GO/GCE), $\mathrm{Ag} / \mathrm{AgCl}(\mathrm{KCl}$ $3.0 \mathrm{~mol} \mathrm{~L}^{-1}$ ) electrode and platinum wire were used as working, reference and auxiliary electrodes, respectively. All experiments were carried out at room temperature $\left(25^{\circ} \mathrm{C}\right)$. The detection experiments with agitation of $1000 \mathrm{rpm}$.

The spectroscopic characterizations of the modified electrodes were carried out in a glassy carbon plates (GC) with area covered of $0.070 \mathrm{~cm}^{2}$, following the same procedure described in item 2.4. Scanning Electron Microscopy (SEM) made the morphological characterization of GC surface modified. A scanning electron microscope with field emission gun (FEG-SEM) of Jeol, model JSM 7500F and energy dispersive X-ray spectroscopy (EDX) module coupled was used for the measurements. Raman spectra were obtained on a LabRAM HR microscopic confocal Raman spectrometer (Horiba Jobin Yvon S.A.S.) employing a $632.8 \mathrm{~nm}$ laser beam. The signal position was calibrated against silicone. The XPS analysis was carried out at a pressure of less than $10^{-7}$ Pa using a commercial spectrometer (UNI-SPECS UHV System, Berlin, Germany). The $\mathrm{Mg} \mathrm{K \alpha}$ line was used $(h v=1253.6 \mathrm{eV})$ and the analyzer pass energy was set to $10 \mathrm{eV}$. The inelastic background of the $\mathrm{C} 1 \mathrm{~s}$ and O 1s electron core-level spectra was subtracted using Shirley's method. The composition (at.\%) of the near surface region was determined with an accuracy of $\pm 10 \%$ from the ratio of the relative peak areas corrected by Scofield's sensitivity factors of the corresponding elements. The binding energy scale of the spectra were corrected using the $\mathrm{C} 1 \mathrm{~s}$ hydrocarbon component of the fixed value of $285.0 \mathrm{eV}$. The spectra were fitted without placing constraints using multiple Voigt profiles. The width at half maximum (FWHM) varied between 1.2 and $2.1 \mathrm{eV}$ and the accuracy of the peak positions was $\pm 0.1 \mathrm{eV}$.

\subsection{Glassy carbon modification with graphene oxide and copper nanoparticles}

Graphene oxide was added onto bare surface of GCE by dropping $2.5 \mu \mathrm{L}$ of a GO-Nafion suspension $0.5 \mathrm{mg} \mathrm{mL}^{-1}$ in ethanol containing $0.30 \%$ in Nafion. After modification, the electrode was dried at room temperature. Parameters such as concentration of Nafion and GO were optimized. Before electrodeposition process, the GCE was immersed in hydrochloridric acid $(37 \% \mathrm{w} / \mathrm{w})$ for one minute to remove metal impurities from the electrode surface, and then the electrode was rinsed with ultrapure water. Graphene oxide suspension $\left(0.50 \mathrm{mg} \mathrm{mL}^{-1}\right)$ in Nafion $0.30 \%$ were added onto GCE surface by dripping $2.5 \mu \mathrm{L}$ of the suspension, according to previous optimization.

The best results for electrodepositing copper nanoparticles on the surface of $\mathrm{GO} / \mathrm{GCE}$ were determined as $-0.7 \mathrm{~V}$ potential for $120 \mathrm{~s}$ in $0.1 \mathrm{~mol} \mathrm{~L}^{-1} \mathrm{H}_{2} \mathrm{SO}_{4}$ solution containing $1 \times 10^{-3} \mathrm{~mol} \mathrm{~L}^{-1}$ $\mathrm{CuSO}_{4} \cdot 5 \mathrm{H}_{2} \mathrm{O}$, according to previous optimization. The resulting electrode was then washed with ultrapure water to remove any adsorbed species. Posteriorly, the NPsCu-GO/GCE were put in $0.1 \mathrm{~mol} \mathrm{~L}^{-1} \mathrm{NaOH}$ solution and scanned repetitively for 30 cycles under potential range from -0.5 to $0.3 \mathrm{~V}$ at $100 \mathrm{mV} \mathrm{s}^{-1}$ for surface passivation [27]. For Comparison, an electrode was modified only with GO (GO/GCE) and another one was modified under the same conditions of the NPsCu-GO/GCE, however, a solution $0.1 \mathrm{~mol} \mathrm{~L}^{-1}$ $\mathrm{H}_{2} \mathrm{SO}_{4}$ without $\mathrm{CuSO}_{4} \cdot 5 \mathrm{H}_{2} \mathrm{O}$ was used (RGO/GCE).

\subsection{Sample pre-treatment}

Residual waters sample was obtained by a sugar and ethanol plant, which was collected from the sugarcane processing for the ethanol production. First, the sample was filtered, to removing impurities and insoluble particles, in Thermo Scientific Titan3 PTFE and Titan2 PTFE filters (Polytetrafluoroethylene) with $0.45 \mathrm{~mm}$ and $0.2 \mathrm{~mm}$ pore size, respectively, both with $30 \mathrm{~mm}$ diameter, and $30 \mathrm{~mm}$ diameter. Then the sample was hydrolyzed using chloridric acid in order to invert the existing sucrose in glucose and fructose, so that sucrose is converted to reducing sugar that can be detected by the proposed method. The sum between glucose, fructose and inverted sucrose characterizes the total reducing sugars.

The procedure adopted for the acid hydrolysis of the sample started with $25 \mathrm{~mL}$ of residual waters, this aliquot was then heated to $67-70^{\circ} \mathrm{C}$ and next was added $5 \mathrm{~mL}$ of $\mathrm{HCl} 37 \%$, remaining in water bath for $5 \mathrm{~min}$. Then, the system was cooled and after that $8 \mathrm{~mL}$ of $\mathrm{NaOH} 30 \%$ was added until it was observed $\mathrm{pH}$ change [28]. The solution was transferred to a $50 \mathrm{~mL}$ volumetric flask, which had its volume completed with ultrapure deionized water.

\subsection{Electrochemical measurements}

For analytical measurements the modification parameters such as concentration of Nafion and GO, suspension volume add on GCE were optimized. Moreover, experimental conditions $\left(\mathrm{CuSO}_{4}\right.$ concentration, electrodeposition time and potential) and instrumental parameters for pulsed amperometry were optimized. The reducing sugars oxidation potential applied for pulsed amperometry detection (PAD) was studied from $0.45 \mathrm{~V}$ to $0.85 \mathrm{~V}$ and the optimal potential was applied as potential detection of reducing sugars.

After preparation, the NPsCu-GO/GCE was characterized by electrochemical impedance spectroscopy (EIS) and studied the electrochemical behavior of glucose and fructose. The electrochemical characterization was performed using EIS with $\mathrm{Fe}(\mathrm{CN})_{6}^{4-/ 3-} 10 \times 10^{-3} \mathrm{~mol} \mathrm{~L}^{-1}$ in $0.1 \mathrm{~mol} \mathrm{~L}^{-1} \mathrm{KCl}$, the applied potential was $0.22 \mathrm{~V}$ vs. $\mathrm{Ag} / \mathrm{AgCl}\left(\mathrm{KCl} 3 \mathrm{~mol} \mathrm{~L}^{-1}\right)$, frequency ranging from 10,000 to $0.1 \mathrm{~Hz}$ in the modified electrode. Study was also performed by $\mathrm{CV}$ with $\mathrm{Fe}(\mathrm{CN})_{6}^{4-13-} 10 \times 10^{-3} \mathrm{~mol} \mathrm{~L}^{-1}$ in $\mathrm{KCl}$ $0.1 \mathrm{~mol} \mathrm{~L}^{-1}$. The electrochemical behavior of analytes was studied using separate solutions of each sugar with concentration of $1 \times 10^{-3} \mathrm{~mol} \mathrm{~L}^{-1}$ in $\mathrm{NaOH} 0.1 \mathrm{~mol} \mathrm{~L}^{-1}$ by $\mathrm{CV}$ with scan rate of $50 \mathrm{mV} \mathrm{s}^{-1}$ in a potential range from $-1.0 \mathrm{~V}$ to $1.0 \mathrm{~V}$.

The sensor response using pulsed amperometry detection was studied in function of the concentration of reducing sugars, with four replicates. Stock solutions of reducing sugars $0.1 \mathrm{~mol} \mathrm{~L}^{-1}$ (fructose and glucose 1:1) were prepared. Standard curves were constructed by addition of $10 \mu \mathrm{L}$ aliquots of reducing sugars solution at regular interval of $20 \mathrm{~s}$ in a cell containing $50 \mathrm{~mL} \mathrm{NaOH}$ $0.1 \mathrm{~mol} \mathrm{~L}^{-1}$ with $1000 \mathrm{rpm}$ stirring. Once the current reached a baseline in the absence of reducing sugars, approximately $100 \mathrm{~s}$, the amperometric current response of the modified electrode was measured by the current difference between the base line and addition of $10 \mu \mathrm{L}$ aliquots of reducing sugars solution. The potentials and time periods for the pulsed amperometric detection were: $E_{1}=0.65 \mathrm{~V}, E_{2}=0.70 \mathrm{~V}$ and $E_{3}=-0.05 \mathrm{~V}$ and all pulses were applied during $100 \mathrm{~ms}$.

The limit of detection (LOD) and the limit of quantification (LOQ) were defined as 3.3 times and 10 times the standard deviation (SD) of the regression line equation divided by slope $(b)$ of the analytical curve, respectively [29]. Other parameters including linearity and correlation coefficients $(R)$ were assessed for the analyte. To determine the concentration and the method's recovery of reducing sugars in sample it was used the standard addition method. 


\section{Results and discussion}

\subsection{Morphological characterization}

Fig. 1(A) shows GCE without modification and Fig. 1(B) and (C) presents the graphene sheets deposited on the surface of the GCE. The wrinkled nature of the graphene sheets is highly favorable since it maintains a high surface area on the electrode since the graphene sheets cannot return to graphitic structure [30], Fig. 1 (B) and (C). Fig. 1(D) shows the NPsCu-GO/GCE at optimized conditions (Supplementary information, Figs. 1 and 2). From the SEM image, it is possible to note that the nanoparticles electrodeposited display sizes between 21 and $152 \mathrm{~nm}$ (300 nanoparticles were counted), and mean diameter of $81 \pm 26 \mathrm{~nm}$, Fig. 2(A). Furthermore, the nanoparticles densely occupy the region around the graphene sheet, but also incorporating it, being detached by small white spots on a layer.

The composition of the GO/GCE and NPsCu-GO/GCE was analysed by EDX analysis. The obtained diffractograms is shown in Fig. 2(B). The chemical composition obtained for GO/GCE indicated mainly carbon, fluorine, oxygen and sulfur. The presence of fluorine and sulfur signals in GO/GCE is due to the Nafion polymer that was used to adhere the GO in the surface of the electrode, and carbon and oxygen signals are due to the GO. In the NPsCu GO/GCE was observed characteristic signals of carbon, fluorine, oxygen, sulfur and copper. This result confirms the modification of the electrode with NPsCu.

Raman spectra of GO/GCE, RGO/GCE and NPsCu-GO/GCE are shows in Fig. 2(C). The bands associated at $\sim 1328, \sim 1600,2677$ and $2922 \mathrm{~cm}^{-1}$ correspond to D (defect band due to intervalley scattering), $G$ (graphene band), $2 D$ and $D+G$ bands, respectively [31-33]. After applying the potential of $-0.7 \mathrm{~V}$, it was observed that the intensity of the D and G bands is not reversed, once graphene oxide is not reduced to graphene. The $D / G$ intensity ratio for RGO/GCE (1.1) remains equal to that obtained for the GO/GCE (1.1), indicating that the defect concentration remained constant and the GO was not reduced. This can be explained by the fact that the $\mathrm{GO}$ be reduced only the most negative potentials than $-1.0 \mathrm{~V}$. When the GO/GCE is modified with copper nanoparticles (NPsCu$\mathrm{GO} / \mathrm{GCE}$ ) is observed that the $\mathrm{D} / \mathrm{G}$ intensity ratio increases from 1.1 to 1.5 . This change in the intensity ratio of the $D / G$ is attributed to the increased defect concentration caused by the modification of the GO with copper nanoparticles. The $2 \mathrm{D}$ ( or $\mathrm{G}^{\prime}$ ) band confirm the presence of graphene and it originates from a double resonance process that links phonons to the electronic band structure and $\mathrm{D}+\mathrm{G}$ band are generally related to point defects in the basal plane or edges of single-crystalline graphene domains $[31,34]$.

The surface chemistry of GO/GCE and RGO/GCE were characterized using XPS in order to investigate the oxidation level and chemical bonding nature. In the XPS spectra of GO/GCE and RGO/ GCE were observed three large peaks at 284.9, 532.4 and $688.9 \mathrm{eV}$ corresponding to the $\mathrm{C} 1 \mathrm{~s}, \mathrm{O} 1 \mathrm{~s}$ and $\mathrm{F} 1 \mathrm{~s}$ (Peak from the Nafion polymer used in the electrode modification) emissions, respectively. The high-resolution $C 1 \mathrm{~s}$ spectra of the samples can be deconvoluted into eight components corresponding to carbon atoms in different functional groups at 282.7 (C-Si), $284.6(\mathrm{C}-\mathrm{C})$, $285.3(\mathrm{C}-\mathrm{H}), 286.7(\mathrm{C}-\mathrm{O}), 287.7(\mathrm{C}=\mathrm{O}), 289.2(\mathrm{O}-\mathrm{C}=0), 291.8$ $\left(\mathrm{CF}_{2}\right)$ and $293.5\left(\mathrm{CF}_{3}\right) \mathrm{eV}$, Fig. 2(D) $[32,33,35]$. After the process of electrochemical reduction, the high-resolution $\mathrm{C} 1 \mathrm{~s}$ spectra of RGO/GCE shows that the intensities of the ethers, epoxides, esters, carboxylic acids and alcohols/phenols groups $(\mathrm{C}-\mathrm{O}, \mathrm{C}=\mathrm{O}$ and $\mathrm{O}-\mathrm{C}=\mathrm{O}$ ) groups suffered a slight increase (approximately constant). It was also observed that the intensities of the aromatic component $(\mathrm{C}-\mathrm{C})$ increased and $\mathrm{sp}^{3}$ carbon groups $(\mathrm{C}-\mathrm{H})$ decreased. The oxygen content was monitored by the $\mathrm{O} 1 \mathrm{~s}$ signal, Fig. 2(D). The high-resolution $\mathrm{O} 1 \mathrm{~s}$ spectra of the samples can be deconvoluted into five components. It was observed four components corresponding to oxygen atoms in different functional groups at $531.6(\mathrm{C}=\mathrm{O}), 532.2(\mathrm{C}-\mathrm{O}), 533.7(\mathrm{O}-\mathrm{C}=\mathrm{O})$ and 535.2 $\left(\mathrm{H}_{2} \mathrm{O}\right) \mathrm{eV}$, and one component potential sodium Auger overlap with $\mathrm{O} 1 \mathrm{~s}$ at 536.0 ( $\mathrm{Na} \mathrm{KLL}$ ) eV which can be from the $\mathrm{NaOH}$ used in passivation of modified electrodes. The quantitative XPS analysis from the $\mathrm{C} 1 \mathrm{~s}$ spectra showed that the oxygen concentration decreases of 24.0 at.\% (GO/GCE) to 20.5 at.\% (RGO/GCE) and the carbon concentration increases of 76.0 at.\% (GO/GCE) to 79.5 at.\% (RGO/GCE). And the $\mathrm{O} / \mathrm{C}$ atomic ratio subtly diminishes of $0.32 \%$ (GO/GCE) to $0.26 \%$ (RGO/GCE) after the modification. These results, combined with RAMAN analysis, indicate that does not hear structural changes significant from graphene oxide (GO/GCE) to graphene (RGO/GCE).

\subsection{Electrochemical characterization}

The cyclic voltammogram for bare CGE shows a reversible redox behavior of an electron to the $\left[\mathrm{Fe}(\mathrm{CN})_{6}\right]^{4-/ 3-}$ in $\mathrm{KCl}$, with peak separation ( $\Delta \mathrm{Ep}$ ) of $76 \mathrm{mV}$ and the peak current divided by the anode current cathodic peak (Ipa/Ipc) equal to 1 . After modification of the CGE with CuNPs only, a decrease of peak current was observed $(\mathrm{Ipa} / \mathrm{Ipc}=0.87)$ as well as greater $\Delta \mathrm{Ep}$, Fig. $3(\mathrm{~A})$. In GO/GCE voltammogram an irreversible redox behavior was observed for [Fe $\left.(\mathrm{CN})_{6}\right]^{4-13-}$ that showed an anodic peak at $270 \mathrm{mV}$ with Ipa equal to $2.23 \mu \mathrm{A}$, this behavior was observed because Nafion is loaded negatively and prevents the diffusion of ferricyanide ions toward the electrode surface [36]. These results indicate that Nafion has a blocking effect of the electrode surface and CuNPs are responsible for improving the electron transfer in GCE modification. The voltammograms shows that there is an effective surface modification of GCE with GO and CuNPs, resulting in the promotion of the electrons transfer between the substance analyzed the NPsCu-GO/ GCE.

The EIS is widely used for information on the transfer of electrons between the electrolyte and the electrode surface. EIS graphics typically include a semicircular part of the Nyquist plot and a linear part, Fig. 3(B, curves $d$ and e). The semicircular part at higher frequencies corresponds to the limited electron transfer process, and the diameter is equivalent to the electron transfer resistance $\left(R_{\mathrm{ct}}\right)$ and the electron transfer process of the redox pair on the electrode surface. The linear part at lower frequencies corresponds to the diffusion process $[19,27]$.

In Fig. 3(B, curve e) is presented the EIS diagram for the GCE modified with GO in the frequency range of $0.1 \mathrm{~Hz}-100 \mathrm{kHz}$. The diagram not present a linear region, indicating no Warburg resistance limiting the diffusion in the electrochemical process. In the EIS diagram for the GO/GCE are observed approximately two semicircle of electron transfer. As the electron transfer at the two interfaces is not very fast, the semicircles are observed. Furthermore, the time constants of the exchange reactions at interfaces not are equal, facilitating the visualization of two semicircles [37]. The first semicircle is related to the electron transfer at the polymer-GO/ solution interface and the second semicircle is related to transfer of ions at the electrode/polymer-GO interface.

The equivalent circuit for an electrode undergoing heterogeneous electron transfer is usually described on the basis of the model by Randles, however, the GO/GCE has not Warburg resistance. The equivalent circuit for the modified electrode with GO includes in series: the solution resistance $\left(R_{\mathrm{s}}\right)$, electron transfer resistance $\left(R_{\mathrm{ct}}\right)$ and capacitance in the polymer-GO/solution interface in parallel. End the constant phase element (CPE) that is associated, in part, with the roughness of the surface of the working electrode, corresponding the modified of the GCE with GO and polymeric film, double-layer capacitance $\left(C_{\mathrm{dl}}\right)$ and electron transfer resistance $\left(R_{\mathrm{ct} 2}\right)$ in the electrode/polymer-GO interface in parallel (Supplementary information, Fig. 3) [37]. 

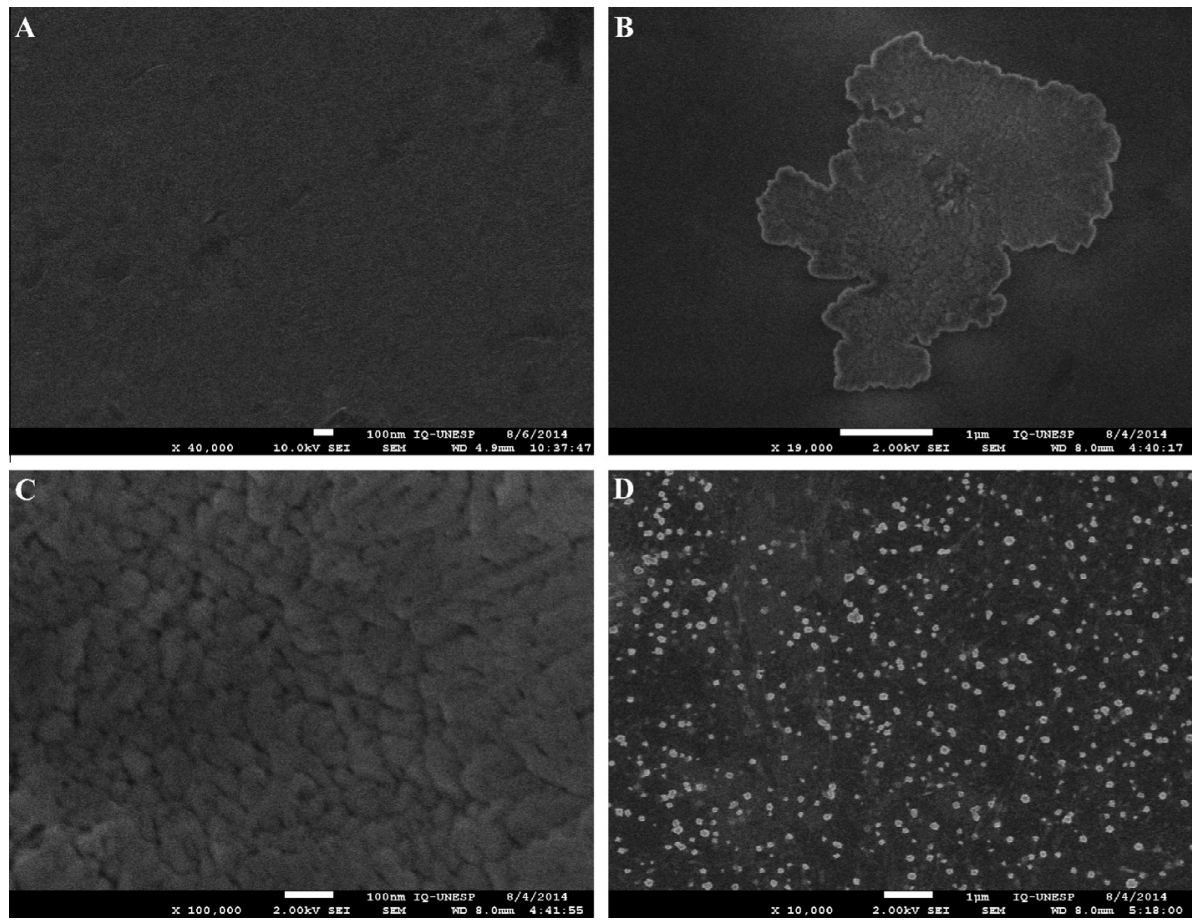

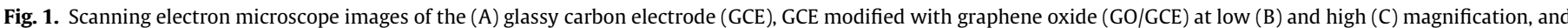
(D) GO/GCE containing copper nanoparticles (NPsCu-GO/GCE).
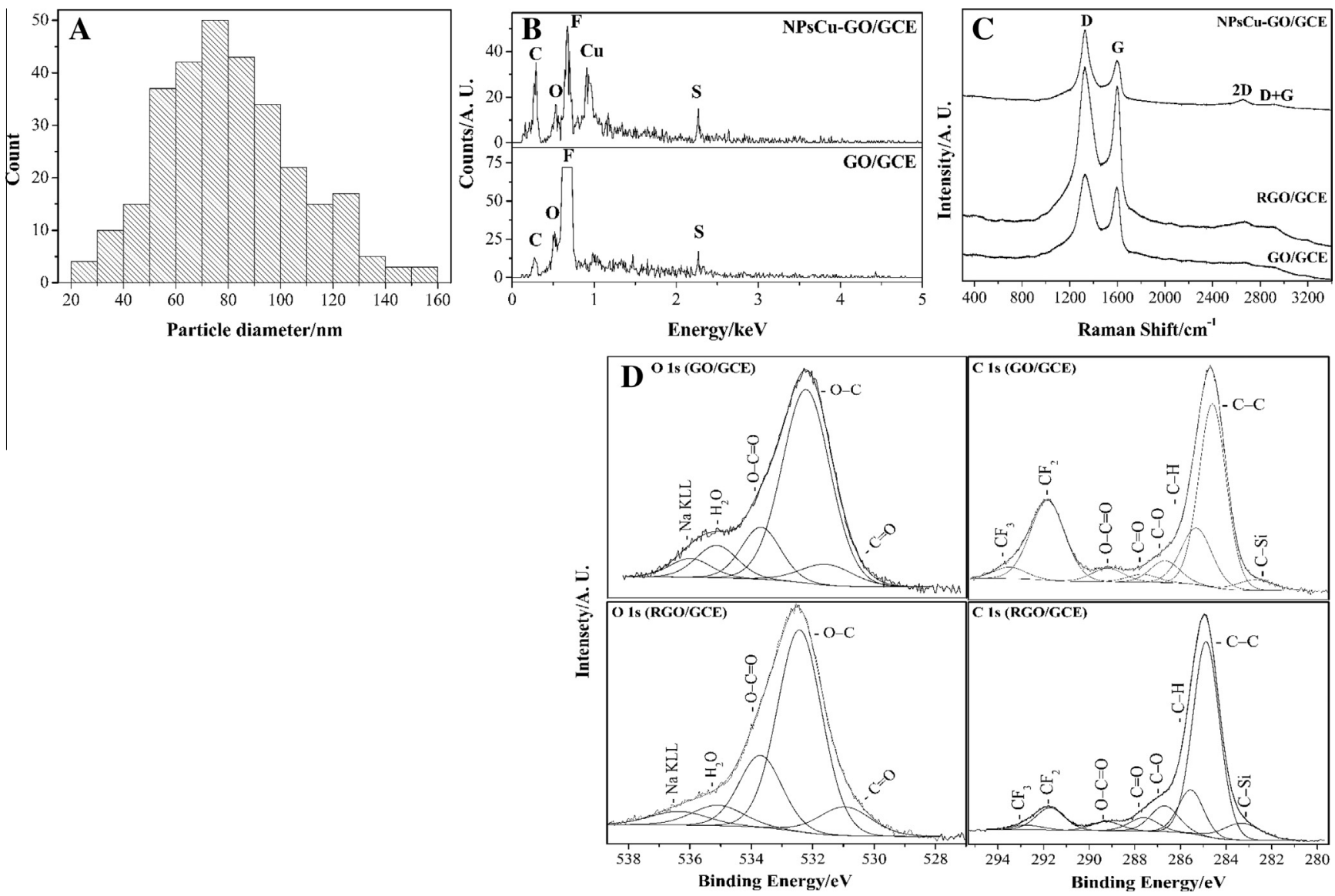

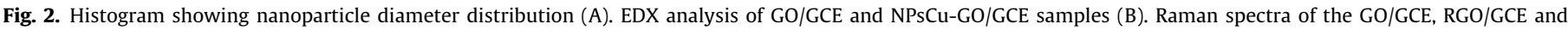
NPsCu-GO/GCE (C). Deconvoluted C 1s and O 1s XPS spectra of the GO/GCE and RGO/GCE (D). 

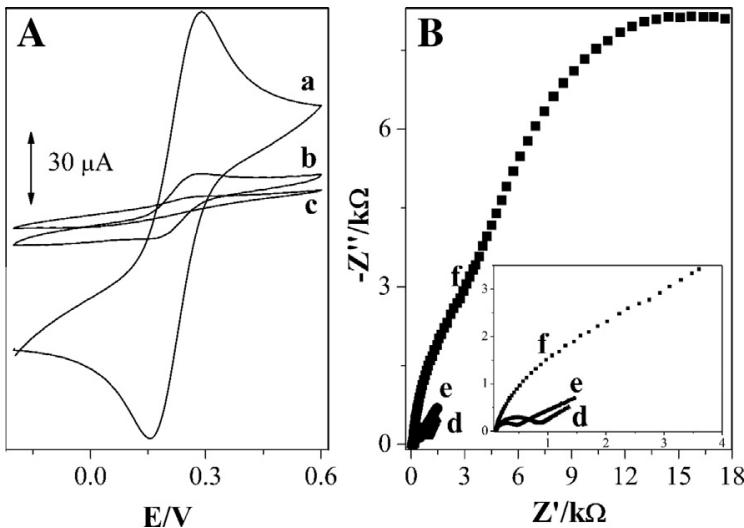

Fig. 3. (A) Cyclic voltammograms of (a) bare GCE, (b) GO/GCE and (c) NPsCu-GO/ $\mathrm{GCE}$ in presence of $\left[\mathrm{Fe}(\mathrm{CN})_{6}\right]^{4-/ 3-}$ in $\mathrm{KCl}, v=50 \mathrm{mV} \mathrm{s}^{-1}$. (B) EIS of (d) bare GCE, (e) $\mathrm{GO} / \mathrm{GCE}$ and (f) $\mathrm{NPsCu}-\mathrm{GO} / \mathrm{GCE}$ in $\left.\mathrm{Fe}(\mathrm{CN})_{6}\right]^{4-/ 3-} 10 \times 10^{-3} \mathrm{~mol} \mathrm{~L}^{-1}$ in $\mathrm{KCl}$ $0.1 \mathrm{~mol} \mathrm{~L}^{-1}$.

The GCE modified with GO exhibits higher $R_{\mathrm{ct}}(5.21 \mathrm{~K} \Omega$, curve e) and compared to unmodified GCE $\left(R_{\mathrm{ct}} 760 \Omega\right)$ is approximately 6.9 times greater, Fig. 3(B, curve d). This result is due to the Nafion used in the modification that can act as a barrier, blocking the interfacial load transfer [36]. Also, Fig. 3(B, curve f) shows that the modification with CuNPs-GO decreased $R_{\mathrm{ct}}$ to $414 \Omega$, indicating that the modification has increased transfer of electrons compared to the modification made only with GO. Moreover, it was observed that CuNPs act as electron mediators in electron transfer process, in other words, the heterogeneous electron transfer capability of graphene sheets is enhanced by incorporating CuNPs [36] and the results indicate the GO and CuNPs were successfully fixed on GCE surface.

\subsection{Electrochemical behaviour of analytes}

The analytes electrochemical behavior investigated on the surface of the NPsCu-GO/GCE compared to the GO/GCE. Fig. 4(A) shows the voltammetric response of the GO/GCE in $\mathrm{NaOH}$ $0.1 \mathrm{~mol} \mathrm{~L}^{-1}$ with a scan speed of $50 \mathrm{mV} \mathrm{s}^{-1}$ in presence or absence of each sugar. It can be seen that the addition of analyte does not cause any effect on the cyclic voltammogram of graphene electrode and no oxidation peak of the analyte is observed, Fig. 4(A). After the electrodeposition of copper nanoparticles on the GO/GCE surface, the electrode began to respond to the presence of carbohydrates, exhibiting characteristic peaks due to the irreversible oxidation process that starts in approximately $0.70 \mathrm{~V}$, Fig. 4(B). Were observed similar results in other studies $[21,38]$. These results suggests that copper nanoparticles play the lead role towards glucose and fructose oxidation due to its electrocatalytic property, whereas graphene improves the electrocatalytic performance of the electrode as a result of its high surface area and high conductivity as well as the fast electron transfer provided by graphene sheets.

The electrocatalytic activity performed by the NPsCu-GO/GCE was studied in the potential range between $0.10 \mathrm{~V}$ and $0.75 \mathrm{~V}$. Fig. 5 shows that in presence of the analyte there is a current increase, where it is possible to note characteristic irreversible oxidation peaks in potential of approximately $0.45 \mathrm{~V}$ to glucose and $0.65 \mathrm{~V}$ to fructose. The mechanism involved in electrocatalytic oxidation of glucose and fructose by copper nanoparticles is not yet known, however the most accepted one was suggested by Marioli and Kuwana [39]. According to the authors, the electrocatalysis occurs via several steps, including the formation of oxidized species $\mathrm{Cu}$ (III), which acts mediating electron transfer [39]. The mechanism starts with the oxidation of copper species.
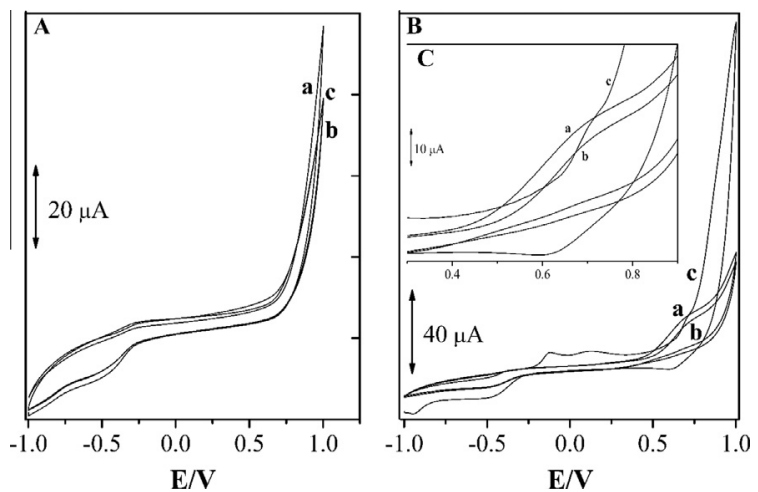

Fig. 4. Cyclic voltammogram of (A) GO/GCE and (B) NPsCu-GO/GCE in $1.0 \times 10^{-3}$ mol L $\mathrm{L}^{-1}$ of (a) glucose, (b) fructose in (c) $\mathrm{NaOH} 0.1 \mathrm{~mol} \mathrm{~L}^{-1}, v=50 \mathrm{mV} \mathrm{s}^{-1}$. (C) Inset shows the region of interest.

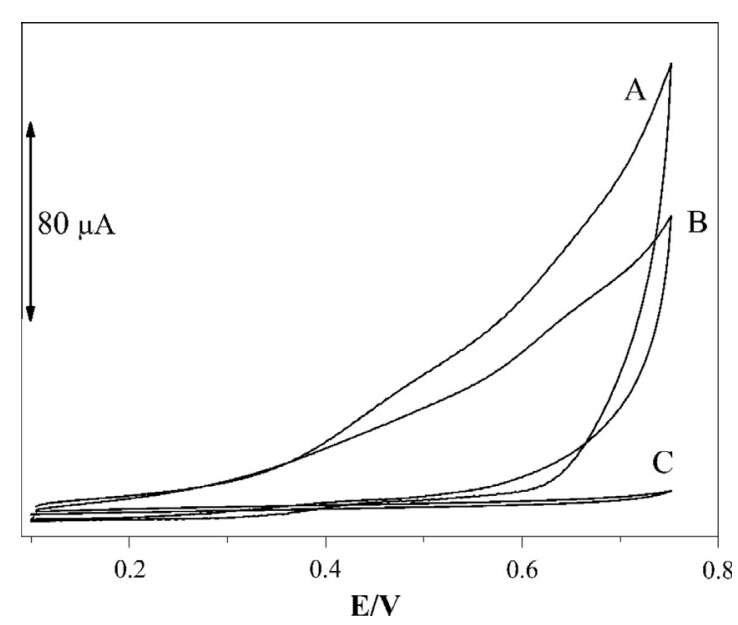

Fig. 5. Cyclic voltammogram of NPsCu-GO/GCE in $1.0 \times 10^{-3} \mathrm{~mol} \mathrm{~L}^{-1}$ of (A) glucose, (B) fructose in (C) NaOH $0.1 \mathrm{~mol} \mathrm{~L}^{-1}, v=50 \mathrm{mV} \mathrm{s}^{-1}$.

$\mathrm{Cu}(\mathrm{II}) \rightleftharpoons \mathrm{Cu}(\mathrm{III})+\mathrm{e}^{-}$

Followed by carbohydrate oxidation:

$\mathrm{Cu}$ (III) + Carbohydrate $\rightarrow$ Intermediate $+\mathrm{Cu}$ (II)

Subsequently, the intermediate oxidizes to the product, glycolic acid and formic acid, by a similar reaction mediated by $\mathrm{Cu}$ (III).

$\mathrm{Cu}$ (III) + Intermediate $\rightarrow$ Product $+\mathrm{Cu}$ (II)

Glucose and fructose oxidation potential in NPsCu-GO/GCE shown in Fig. 5 is in agreement with the potential range where $\mathrm{Cu}$ (II) oxidize to $\mathrm{Cu}$ (III) which is from $0.40 \mathrm{~V}$ to $0.80 \mathrm{~V}$ [39,40], that indicates that there's a relationship between the formation of $\mathrm{Cu}$ (III) and the oxidation electrocatalysis as proposed by Marioli and Kuwana [39]. The anodic peak current to glucose was $19.0 \mu \mathrm{A}$, as for fructose was $5.9 \mu \mathrm{A}$. These results shows that the electrode modification process exercised indeed an important role in sugars oxidation.

\subsection{Pulsed amperometry detection}

Reducing sugars are detected by measuring the electrical current generated through their oxidation on the surface of the NPsCu-GO/GCE. The products of this oxidation reaction can poison the surface of the electrode, and as such, it has to be cleaned between measurements. The PAD solves this problem of activity lost for scoring alternate the anode and cathode polarization, and 
thus promoting cleanliness and reactivation of the electrode surface during application of the pulses [24-26].

An investigation was initially carried out on the potential of detection of the reducing sugars (Supplementary information, Fig. 4) and the best pulse sequence applied in the determination was optimized thereafter. PAD thus employs a sequence of three potentials. The first potential $\left(E_{1}\right)$ is where the reducing sugars are oxidized. The second potential $\left(E_{2}\right)$ seeks oxidize all the species present on the electrode surface and prevent them from being adsorbed. The third potential $\left(E_{3}\right)$ should be low enough to reduce the oxidized surface of the electrode and increase the selectivity and stability of the electrochemical signal [27]. As the electrode was formed from copper oxides, not more than the negative potential of $-0.05 \mathrm{~V}$ was applied for only $100 \mathrm{~ms}$, because in most negative potential the copper species can dissolve in the supporting electrolyte. The potential of $0.65 \mathrm{~V}$ chosen to detect reducing sugars presented higher detectability. So, the potentials and time periods for the PAD were: $E_{1}, 0.65 \mathrm{~V} ; E_{2}, 0.70 \mathrm{~V} ; E_{3},-0.05 \mathrm{~V}$. And time periods were applied during $100 \mathrm{~ms}$.

\subsection{Stability of the modified electrode}

The stability of the NPsCu-GO/GCE was carried out by PAD method. The response of the NPsCu-GO/GCE was assessed in single glucose and fructose solutions. After a period of $100 \mathrm{~s}$ to stabilize the current, $1.0 \times 10^{-3} \mathrm{~mol} \mathrm{~L}^{-1}$ of glucose and fructose were added in supporting electrolyte of $0.1 \mathrm{~mol} \mathrm{~L}^{-1} \mathrm{NaOH}$. The response time between the addition of the sugars and the response of the modified electrode was $5.9 \mathrm{~s}$ and $9.2 \mathrm{~s}$ for glucose and fructose, respectively. And remained stable for $1000 \mathrm{~s}$, indicating the stability of the electrode, with $5.3 \%$ loss of signal for glucose and $4.8 \%$ for fructose.

\subsection{Development of the analytical method}

The analytical parameters of the method developed were evaluated by means of analytical curves. Concentrations were studied within the range of $2.0 \times 10^{-5} \mathrm{~mol} \mathrm{~L}^{-1}$ to $4.4 \times 10^{-4} \mathrm{~mol} \mathrm{~L}^{-1}$. The amperometric response of the NPsCu-GO/GCE for successive additions of reducing sugars (glucose and fructose) are shown in Fig. 6 (A). At $0.65 \mathrm{~V}$, the modified electrode shows a significantly larger current response with the addition of glucose and fructose, which responds very quickly to the changes in analytes in lower concentrations as well as in high concentrations. Fig. 6(A) shows that a well-defined, relatively stable amperometric response was observed for the NPsCu-GO/GCE at $0.65 \mathrm{~V}$. In addition, another attractive feature is reflected by its fast response time towards the oxidation of reducing sugars, the electrode nearly responds immediately after the solution containing fructose and glucose was added, indicating an extraordinarily fast rapid and sensitive response to reducing sugars. The time required to achieve the steady-state was approximately $10 \mathrm{~s}$.

The calibration curve for the sensor is shown in Fig. 6(B). The linear range for the detection of the reducing sugars is $4.0 \times 10^{-5}$ to $3.2 \times 10^{-4} \mathrm{~mol} \mathrm{~L}^{-1}$. The linear regression equation for reducing sugars was $I(\mathrm{~A})=-2.65 \times 10^{-7}+1.51 \times 10^{-2} \mathrm{C}$ with a correlation coefficient of 0.999 . The upper reducing sugars concentration limit for linear response was $4.4 \times 10^{-4} \mathrm{~mol} \mathrm{~L}^{-1}$ and the detection limit was $1.6 \times 10^{-5} \mathrm{~mol} \mathrm{~L}^{-1}$, other analytical parameters are show in Table 1 . The amperometric sensitivity (AS) of the method was evaluated in three different NPsCu-GO/GCE in order to verify the reproducibility of detection. The value obtained in this study was $1.51 \times 10^{-2} \pm 1.7 \times 10^{-4} \mathrm{~A} \mathrm{~mol}^{-1} \mathrm{~L}$ for the reducing sugars, with a coefficient of variation of $1.1 \%$. These results demonstrated that three modified electrodes used for the PAD had standard deviation which did not interfere with the method. It can be noted that the

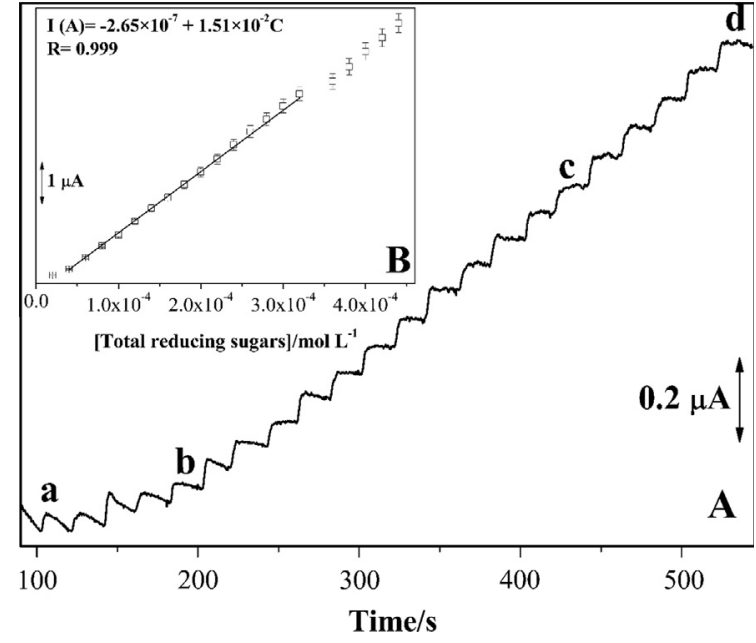

Fig. 6. (A) Cronoamperograms of successive additions of reducing sugars in $\mathrm{NaOH}$ $0.1 \mathrm{~mol} \mathrm{~L}^{-1}$ using NPsCu-GO/GCE: (a) $2.0 \times 10^{-5}$; (b) $1.0 \times 10^{-4}$; (c) $3.2 \times 10^{-4}$; (d) $4.4 \times 10^{-4}$. (B) Inset shows the calibration curve. Detection potential of $0.65 \mathrm{~V}$ and $1000 \mathrm{rpm}$ stirring.

proposed sensor exhibits a very fast response, excellent detection and quantification limits as well as great linear correlation and wide linear range. The detection limit was satisfactory when compared with electrochemical and spectrophotometric methods for determination of sugars described in the literature, Table 2.

\subsection{Interferential analysis}

One of the important analytical factors for an amperometric sensor is its ability to discriminate the interfering species having electroactivities similar to the target analyte. The specificity of the sensor was investigated using an interferent that normally co-exist with reducing sugars in sugarcane broth, sucrose. Despite being a non-reducing sugar, sucrose can be oxidized in the presence of metal oxides such as copper oxide [40]. Although sucrose is hydrolysed before the detection of total reducing sugars in sample, the interest of this study was to assess the potential interference that remaining sucrose could cause in detection.

The interference experiments were carried out by successive addition of $0.2 \mathrm{~mol} \mathrm{~L}^{-1}$ reducing sugar and $2.4 \times 10^{-2} \mathrm{~mol} \mathrm{~L}^{-1}$ interfering specie in a cell containing $50 \mathrm{~mL} \mathrm{NaOH} 0.1 \mathrm{~mol} \mathrm{~L}^{-1}$. The successive additions of sucrose were made at different volumes, resulting in a concentration of interfering specie ranging from $10 \%$ to $100 \%$. The measured effects of sucrose along with reducing sugars at $0.65 \mathrm{~V}$, Fig. 7 . The NPsCu-GO/GCE did not show any significant decline in the sensor response, and the current responses due to the addition of the interfering specie ranged from $5.3 \%$ to $18.6 \%$ compared to reducing sugars at $0.65 \mathrm{~V}$. These results indicate that the NPsCu-GO/GCE is highly specific to reducing sugars since that sucrose, even in large concentrations, does not cause such a large sensor response as the reducing sugars does.

\subsection{Sample analysis}

The methodology developed by PAD was used for determination of total reducing sugars in hydrolysed residual waters sample from the processing of sugarcane using the standard addition method. An aliquot of $25 \mathrm{~mL}$ of the hydrolyzed sample was diluted in distilled water in a $50 \mathrm{~mL}$ volumetric flask. Then, $500 \mu \mathrm{L}$ of the diluted sample solution was added, after that, $40 \mu \mathrm{L}$ of the $0.1 \mathrm{~mol} \mathrm{~L}^{-1}$ standard solution of reducing sugars were made successively. Standard solutions concentrations were chosen so 
Table 1

Calibration curve analytical parameters for pulsed amperometric detection of reducing sugars.

\begin{tabular}{|c|c|c|c|c|c|}
\hline Analyte & Linear range $\left(\mathrm{mol} \mathrm{L}^{-1}\right)$ & $\mathrm{LOD}\left(\mathrm{mol} \mathrm{L}^{-1}\right)$ & $\mathrm{LOQ}\left(\mathrm{mol} \mathrm{L}^{-1}\right)$ & $\mathrm{AS}\left(\mathrm{A} \mathrm{mol}^{-1} \mathrm{~L}\right)$ & Linear correlation \\
\hline Reducing sugars & $2.0 \times 10^{-5}-4.4 \times 10^{-4}$ & $1.6 \times 10^{-5}$ & $4.8 \times 10^{-5}$ & $1.6 \times 10^{-2}$ & 0.999 \\
\hline
\end{tabular}

$\mathrm{LOD}=$ Limit of detection, $\mathrm{LOQ}=$ Limit of quantification, $\mathrm{AS}=$ Amperometric sensitivity .

Table 2

Analytical parameters for sugars determination by different techniques.

\begin{tabular}{|c|c|c|c|c|}
\hline Electrode & Technique & Analyte & $\begin{array}{l}\text { LOD } \\
\left(\mu \mathrm{mol} \mathrm{L}{ }^{-1}\right)\end{array}$ & Reference \\
\hline CuOG-SPCE & $\mathrm{FIA}^{\mathrm{a}}$ & Glucose & 0.34 & {$[41]$} \\
\hline GC/MWCNT/NiO & $C A^{b}$ & Glucose & 160 & {$[42]$} \\
\hline $\begin{array}{l}\text { GOD-graphene- } \\
\text { chitosan }\end{array}$ & $\mathrm{CV}^{\mathrm{c}}$ & Glucose & 20 & [43] \\
\hline Non-electrode & FIS $^{\mathrm{d}}$ & Glucose & 0.56 & {$[44]$} \\
\hline Non-electrode & FIS & Fructose & 2.22 & [44] \\
\hline Glu-PPD/GCE & $\mathrm{DPV}^{\mathrm{e}}$ & Glucose & 0.185 & [45] \\
\hline NPsCu-GO/GCE & PAD & $\begin{array}{l}\text { Reducing } \\
\text { sugars }\end{array}$ & 16 & This work \\
\hline
\end{tabular}

a Flow-injection analysis.

b Chronoamperometry.

c Cyclic voltammetric.

d Flow injection spectrophotometric.

e Differential pulse voltammetry.

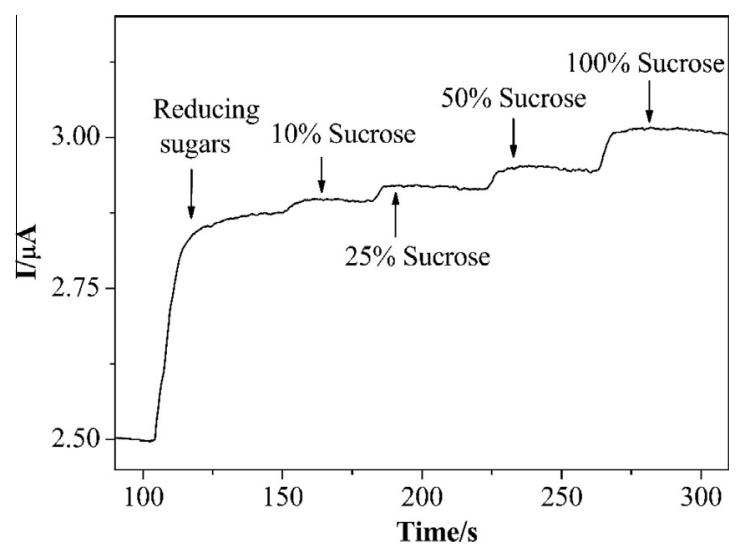

Fig. 7. Interferential analysis in $0.1 \mathrm{~mol} \mathrm{~L}^{-1} \mathrm{NaOH}$ using NPsCu-GO/GCE. Detection potential of $0.65 \mathrm{~V}$ and $1000 \mathrm{rpm}$ stirring.

that the final concentration in cell was within the linear response range, Fig. 8(A). The curve for the method of standard addition for reducing sugars has linear equation, $y=1.9 \times 10^{2} \mathrm{C}$ $+2.0 \times 10^{-6}$ and correlation linear of 0.997 , Fig. 8(B). The developed method using NPsCu-GO/GCE using PAD technique showed that the concentration of total reducing sugars detected in residual waters sample was $2.2 \times 10^{-2} \pm 3.7 \times 10^{-4} \mathrm{~mol} \mathrm{~L}^{-1}$.

Validation is important to demonstrate the suitability of a method for the intended purpose, so in addition, the obtained results were validated by recovery study. The recovery is associated with accuracy, because this test evaluates the proximity between the results obtained by the studied method and the real value. Accuracy is expressed as a percentage of systematic error inherent in the process. The systematic error may be due to loss of substance, inaccurate volume measurements or interfering substances in the sample [46].

In the recovery test for reducing sugars in sample, the sample was spiked with different concentrations of a standard reducing

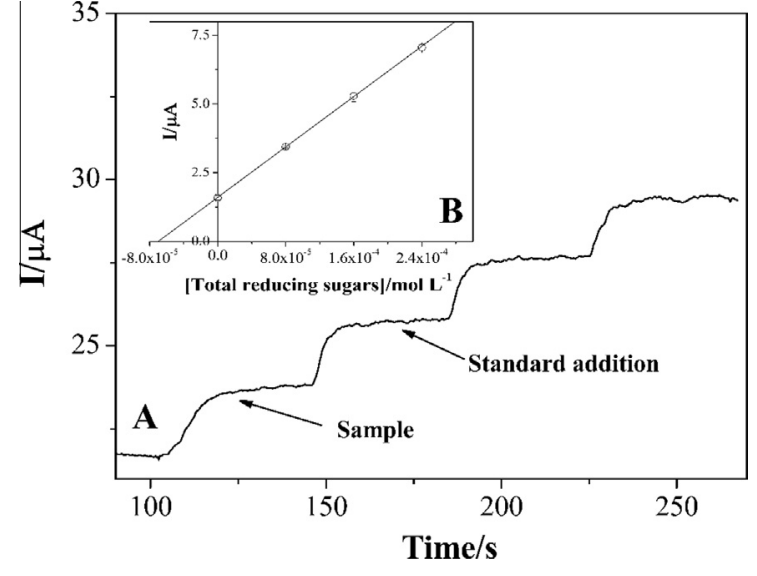

Fig. 8. (A) Cronoamperograms of real sample with successive additions of reducing sugars in $\mathrm{NaOH} 0.1 \mathrm{~mol} \mathrm{~L}^{-1}$ using NPsCu-GO/GCE. (B) Inset shows the Standard addition curve. Detection potential of $0.65 \mathrm{~V}$ and $1000 \mathrm{rpm}$ stirring.

sugars solution (glucose and fructose 1:1), ranging from $8.0 \times 10^{-5}$ to $2.4 \times 10^{-4} \mathrm{~mol} \mathrm{~L}^{-1}$. The sample was assessed in triplicate. Recovered value was $92.8 \pm 0.5 \%$ for reducing sugars. This result indicates that the developed method for reducing sugars detection using a modified glassy carbon electrode is highly accurate for the range of concentrations and evaluated sample, moreover, it was possible to notice from these results that other electroactive species possibly present in the matrix, such as sucrose, not significantly interfere in the determination of reducing sugars.

\subsection{Comparison with other technique}

Ion exchange liquid chromatography was used to validate the developed method using modified electrode and PAD, the chromatographic determination was made by standard addition method. The residual waters sample was analysed by the chromatograph in order to determine its concentration in total reducing sugars to compare with the result obtained by the proposed method.

The total reducing sugars concentration determined in residual waters sample by the pulsed amperometric method using the proposed modified electrode method showed small error in relation to the value determined by the chromatographic method. The statistical evaluation of the obtained results was made using the Student's $t$-test and F-test in order to compare the mean value obtained by both methods and evaluate if there is significant differences between them in terms of accuracy, Table 3 . The results agreed within an acceptable range, showing the reliability as well as the importance of pulsed amperometry method using the modified electrode developed, as the results shows, Table 3 . It is observed that both the $F$ test as in the $t$ test the calculated values for the sample are lower than the critical value at $95 \%$ confidence level. Therefore, this result confirms the acceptable accuracy for the proposed method. 
Table 3

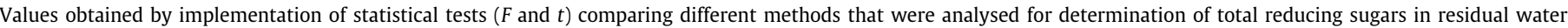
samples.

\begin{tabular}{|c|c|c|c|c|c|c|}
\hline \multirow[t]{2}{*}{ Method } & \multirow[t]{2}{*}{ Mean $\left(\mathrm{mol} \mathrm{L}^{-1}\right)$} & \multirow[t]{2}{*}{ Variancea } & \multicolumn{2}{|l|}{${ }^{\mathrm{a}} \mathrm{F}$} & \multicolumn{2}{|l|}{${ }^{\mathrm{b}} t$} \\
\hline & & & Calculated & Critical & Calculated & Critical \\
\hline Pulsed Amperometry & $2.2 \times 10^{-2}$ & $2.3 \times 10^{-7}$ & 1.68 & 9.28 & 0.39 & 2.45 \\
\hline Ion exchange liquid chromatography & $2.1 \times 10^{-2}$ & $1.3 \times 10^{-7}$ & & & & \\
\hline
\end{tabular}

a $n=3$.

b $n=6$ where $n=$ degrees of freedom.

\section{Conclusions}

The developed method for the determination of total reducing sugars using NPsCu-GO/GCE by pulsed amperometry detection showed low LOD and high amperometric sensitivity. Furthermore, the developed modified electrode showed also quick response, selective, since it had little interference in the presence of other electroactive species.

Given the information obtained by this paper, we conclude that the NPsCu-GO/GCE was successfully applied for the determination of total reducing sugars in residual waters samples obtained from the processing of sugarcane. The obtained results showed that the developed method is very promising for the determination of total reducing sugars not only residual waters samples, but also in different samples from various stages of the processing of sugarcane, in view of its sensitivity, accuracy, speed and simplicity compared to classical methods currently used for such determination.

\section{Acknowledgements}

The authors would like to thank the LMA-IQ, LEFE and Laboratório de Espectroscopia (Institute of Chemistry, UNESP, Brazil) for FEG-SEM, XPS and Raman facilities. This work was financial supported by Fundação de Amparo à Pesquisa do Estado de São Paulo (FAPESP) (Process 2013/22846-9) and CNPq - Brazil.

\section{Appendix A. Supplementary material}

Supplementary data associated with this article can be found, in the online version, at http://dx.doi.org/10.1016/j.fuel.2015.09.046.

\section{References}

[1] Nicoletti G, Arcuri N, Nicoletti G, Bruno R. A technical and environmental comparison between hydrogen and some fossil fuels. Energy Convers Manage 2015;89:205-13.

[2] Naik SN, Goud VV, Rout PK, Dalai AK. Production of first and second generation biofuels: a comprehensive review. Renew Sustain Energy Rev 2010;14:578-97.

[3] Srivastava AK, Rai MK. Review - sugarcane production: impact of climate change and its mitigation. Biodiversitas 2012;13:214-27.

[4] Zarpelon F, Stupiello JP, Baccharim LM, Silva JFJ, Pasquot LC, Bezerra LA. Controle químico da fabricação do açúcar. São Paulo: COPERSUCAR: 1978.

[5] Lane JH, Eynon L. Determination of reducing sugars by Fehling solution with methylene blue indicator. London: Norman Rodger; 1934.

[6] Miller GL. Use of dinitrosalicyclic reagent for determination of reducing sugar. Anal Chem 1959;31:426-8.

[7] Nelson N. A Photometric adaptation of the Somogyi methgod for the determination of Glucose. J Biol Chem 1944;153:375-80.

[8] Somogyi M. Determination somogyi. J Biol Chem 1945;160:61-8.

[9] McClements DJ. Analysis of Carbohydrates n.d. <http://people.umass.edu/ mcclemen/581Carbohydrates.html>.

[10] Cao F, Gong J. Nonenzymatic glucose sensor based on CuO microfibers composed of CuO nanoparticles. Anal Chim Acta 2012;723:39-44.

[11] Wang Y, Wang W, Song W. Binary CuO/Co3O4 nanofibers for ultrafast and amplified electrochemical sensing of fructose. Electrochim Acta 2011;56:10191-6

[12] Stitz A, Buchberger W. Determination of sugars, sugar degradation products and alcohols by high-performance liquid chromatography with electrochemical detection. Fresen J Anal Chem 1991;339:55-7.
[13] You T, Niwa O, Chen Z, Hayashi K, Tomita M, Hirono S. An amperometric detector formed of highly dispersed $\mathrm{Ni}$ nanoparticles embedded in a graphitelike carbon film electrode for sugar determination. Anal Chem 2003;75:5191-6.

[14] Baldwin RP, Thomsen KN. Chemically modified electrodes in liquid chromatography detection: a review. Talanta 1991;38:1-16.

[15] Cheng Q, Wu C, Chen J, Zhou Y, Wu K. Electrochemical tuning the activity of nickel nanoparticle and application in sensitive detection of chemical oxygen demand. J Phys Chem C 2011;115:22845-50.

[16] Xi L, Wang F, Zhu Z, Huang Z, Zhu Y. Ion-exchange chromatography combined with direct current amperometric detection at CuNPs/reduced graphene oxide-chitosan composite film modified electrode for determination of monosaccharide composition of polysaccharides from Phellinus igniarius. Talanta 2014:119:440-6.

[17] Campbell FW, Compton RG. The use of nanoparticles in electroanalysis: an updated review. Anal Bioanal Chem 2010;396:241-59.

[18] Marioli JM, Luo PF, Kuwana T. Nickel-chromium alloy electrode as a carbohydrate detector for liquid chromatography. Anal Chim Acta $1993 ; 282: 571-80$

[19] Rochefort A, Wuest JD. Interaction of substituted aromatic compounds with graphene. Langmuir 2009:25:210-5.

[20] Lu J, Do I, Drzal LT, Worden RM, Lee I. Nanometal-decorated exfoliated graphite nanoplatelet based glucose biosensors with high sensitivity and fast response. ACS Nano 2008;2:1825-32.

[21] Luo J, Jiang S, Zhang H, Jiang J, Liu X. A novel non-enzymatic glucose sensor based on $\mathrm{Cu}$ nanoparticle modified graphene sheets electrode. Anal Chim Acta 2012;709:47-53.

[22] Sun CL, Cheng WL, Hsu TK, Chang CW, Chang JL, Zen JM. Ultrasensitive and highly stable nonenzymatic glucose sensor by a CuO/graphene-modified screen-printed carbon electrode integrated with flow-injection analysis. Electrochem Commun 2013;30:91-4.

[23] Chen Q, Zhang L, Chen G. Facile preparation of graphene-copper nanoparticle composite by in situ chemical reduction for electrochemical sensing of carbohydrates. Anal Chem 2012;84:171-8.

[24] Johnson DC, LaCourse WR. Liquid chromatography with pulsed electrochemical detection at gold and platinum electrodes. Anal Chem 1990;62:589A-97A.

[25] Johnson DC, LaCourse WR. Pulsed electrochemical detection at noble meta electrodes in liquid chromatography. Electroanalysis 1992;4:367-80.

[26] LaCourse WR. Origins of pulsed potential cleaning. In: Pulsed electrochemica detection in high performance liquid chromatography. New York: John Wiley \& Sons; 1997.

[27] Beluomini MA, Luiz da Silva J, Stradiotto NR. Determination of uronic acids in sugarcane bagasse by anion-exchange chromatography using an electrode modified with copper nanoparticles. Anal Meth 2015;7:2347-53.

[28] Demiate IM, Wosiacki G, Czelusniak C, Nogueira A. Analysis of total and reducing sugar in foods A comparative study between colorimetric and titration techniques. Exact Soil Sci Agrar S Eng 2002;8:65-78.

[29] Ribani M, Grespan Bottoli CB, Collins CH, Fontes Jardim ICS, Costa Melo LF. Validação em métodos cromatográficos e eletroforéticos. Quim Nova 2004;27:771-80.

[30] Yin $\mathrm{H}$, Zhou Y, Ma O Ai S, Ju P, Zhu L, et al. Electrochemical oxidation behavior of guanine and adenine on graphene-Nafion composite film modified glassy carbon electrode and the simultaneous determination. Process Biochem 2010;45:1707-12

[31] Luo J, Zhang $H$, Jiang S, Jiang J, Liu X. Facile one-step electrochemica fabrication of a non-enzymatic glucose-selective glassy carbon electrode modified with copper nanoparticles and graphene. Microchim Acta 2012;177:485-90.

[32] Hilder M, Winther-Jensen B, Li D, Forsyth M, MacFarlane DR. Direct electrodeposition of graphene from aqueous suspensions. Phys Chem Chem Phys 2011;13:9187-93.

[33] Zhang X, Zhang D, Chen Y, Sun X, Ma Y. Electrochemical reduction of graphen oxide films: preparation, characterization and their electrochemical properties. Chin Sci Bull 2012;57:3045-50.

34] Kiraly B, Iski EV, Mannix AJ, Fisher BL, Hersam MC, Guisinger NP. Solid-source growth and atomic-scale characterization of graphene on $\operatorname{Ag}(111)$. Nat Commun 2013;4:1-7.

[35] Pendashteh A, Mousavi MF, Rahmanifar MS. Fabrication of anchored copper oxide nanoparticles on graphene oxide nanosheets via an electrostatic 
coprecipitation and its application as supercapacitor. Electrochim Acta 2013;88:347-57.

[36] Kang X, Mai Z, Zou X, Cai P, Mo J. A sensitive nonenzymatic glucose sensor in alkaline media with a copper nanocluster/multiwall carbon nanotubemodified glassy carbon electrode. Anal Biochem 2007;363:143-50.

[37] Girotto EM, Paoli M-A De. Transporte de massa em polímeros intrinsecamente condutores: importância, técnicas e modelos teóricos. Quim Nova $1999 ; 22: 358-68$

[38] Yang J, Jiang LC, Zhang WD, Gunasekaran S. A highly sensitive non-enzymatic glucose sensor based on a simple two-step electrodeposition of cupric oxide (CuO) nanoparticles onto multi-walled carbon nanotube arrays. Talanta 2010;82:25-33.

[39] Marioli JM, Kuwana T. Electrochemical characterization of carbohydrate oxidation at copper electrodes. Electrochim Acta 1992;37:1187-97.

[40] Male KB, Hrapovic S, Liu Y, Wang D, Luong JHT. Electrochemical detection of carbohydrates using copper nanoparticles and carbon nanotubes. Anal Chim Acta $2004 ; 516: 35-41$

[41] Sun C-L, Cheng W-L, Hsu T-K, Chang C-W, Chang J-L, Zen J-M. Ultrasensitive and highly stable nonenzymatic glucose sensor by a $\mathrm{CuO} /$ graphene-modified screen-printed carbon electrode integrated with flow-injection analysis. Electrochem Commun 2013;30:91-4.

[42] Shamsipur M, Najafi M, Hosseini M-RM. Highly improved electrooxidation of glucose at a nickel(II) oxide/multi-walled carbon nanotube modified glassy carbon electrode. Bioelectrochemistry 2010;77:120-4.

[43] Kang X, Wang J, Wu H, Aksay IA, Liu J, Lin Y. Glucose oxidase-graphenechitosan modified electrode for direct electrochemistry and glucose sensing. Biosens Bioelectron 2009;25:901-5.

[44] Liu J, Jiang G. Spectrophotometric flow injection determination of total reducing sugars in tobacco based on oxidation by ferricyanide and formation of Prussian blue. Anal Lett 2001;34:1923-34.

[45] Wang Q Paim LL, Zhang X, Wang S, Stradiotto NR. An electrochemical sensor for reducing sugars based on a glassy carbon electrode modified with electropolymerized molecularly imprinted poly-o-phenylenediamine film. Electroanalysis 2014;26:1612-22.

[46] Brito NM, Amarate Junior OP, Polese L, Ribeiro ML. Validação de métodos analíticos: Estratégia e discussão. Pestic Rev Ecotoxicologia E Meio Ambient 2003;13:129-46. 